\title{
Delivering Self-Management Health Outcomes Using the Patient Activation Measure Instrument - Prospects for the Dentistry Field
}

\author{
Antoniadou Maria* \\ Dental School, National and Kapodistrian University of Athens, Greece
}

Submission: March 04, 2020; Published: March 17, 2020

*Corresponding author: Antoniadou Maria, Dental School, National and Kapodistrian University of Athens, Greece

\section{Abstracts}

Patient activation (PA) can lead people to enjoy better life quality even while facing chronic pain and serious illnesses. This requires a high level of knowledge, skill and confidence. Clinicians when encouraging patient engagement in their care they do so blinded to any information on the patients' capabilities for taking on a self-management role. For this reason, certain measurement instruments have been developed.

In this article, the role of the well-known Patient Activation Measure (PAM), and its 13-item short form, is being reviewed in the field of general medicine in order to explore its possible applications also in the field of dentistry. In general, the use of the PAM13 instrument on patients with chronic diseases succeeds in improving general health. It seems that patients can benefit from coaching through its use. But people with mental, heart or chronic pain problems may require more support for self-management from their care teams. Furthermore, improved access for national primary care systems' doctors to self-management tools can facilitate patient' skills development. Importantly, oral health application of PAM13 should be checked as a future research tool for controlling oral health diseases that contribute to loss of teeth, like caries, periodontitis and peri-implantitis.

Keywords: Dental patient education, Medical counseling, Patient activation, Chronic illnesses, dental caries, Periodontitis, Peri-imlpantitis, Patient activation measure, PAM, PAM13 Instrument, Self-care management

Abbreviations: PAM: Patient activation measure; PA: Patient activation; CDSM: chronic disease self-management; SRIT: Self-referral to inpatient treatment; CMHC: Community Mental health Centers; WMI: Weight management intervention; CR: Cardiac rehabilitation; CABS: Coronary artery bypass surgery; PCI: Percutaneous coronary intervention; COPD: Chronic Obstructive Pulmonary Disease; MRC: Medical Research Council; IBD: Inflammatory bowel diseases; PD: Parkinson's disease; ASCVD: Atherosclerotic cardiovascular disease; PCPs: primary care physicians ; TSRQ: Treatment Self-Regulation Questionnaire; RA: Rheumatoid arthritis; HF: Heart failure; IMD: Index of Multiple Deprivation

\section{Introduction}

Patients can have a serious role in managing their own health and their need for care, but they have to be educated on how to do so. They can learn to perform a guided self-coaching approach in order to support their accountability in life changes and new health and diet habits. By experiencing small successes and building self-confidence and self-management in their day to day lives, patients can cooperate better with the health clinicians and relevant staff [1]. Patient activation (PA) can finally lead them to enjoy better life quality even while facing chronic pain and serious illnesses. Of course, effectively functioning in the role of self-manager, particularly when living with one or more chronic illnesses, requires a high level of knowledge, skill and confidence [1]. Yet, when clinicians encourage patient engagement in their care, they do so blind to any information on the patients' capabilities for taking on a self-management role. So, PA was a "one size fits all" patient education approach until recently. But as with other dimensions of quality, the ability to measure one's self managing role, is essential. For this reason, certain measurement instruments have been developed so far. In this article, the role of such an instrument, the well-known Patient Activation Measure (PAM), is being reviewed in the field of general medicine in order to explore its possible applications also in the field of dentistry. In the dental field, only few data exist on PA and its response to 
altering the oral health profile of people [2]. Taking into account that the world's population is aging much faster than in the past and by $2050,80 \%$ of older people will be living in low- and middleincome countries like Greece, it seems absolutely necessary to improve PA and self-management of chronic health situations in order to cut down expenses from their general and dental health and social systems. These systems are already facing major challenges, trying to ensure that they can make the most of this demographic shift [3] and the future is not fruitful for them on overcoming major economical weights.

\section{The Patient Activation Measure instrument (PAM)}

For well over two decades, researchers and policy makers have recognized that people with chronic illness have a central role in determining their care outcomes through a process of chronic disease self-management (CDSM). CDSM requires that a person with a chronic disease adopts a set of attitudes, behaviors and skills to effectively self-manage his condition [4-8]. Central to the self-management process, is patient-activation (PA), through supportive health care systems in which healthcare providers empower patients to actively participate in the management of their own condition [9-13]. PA is defined as "the ability (of the healthcare provider) to activate the patient to take control in the consultation and/or in the management of their condition" [10]. $\mathrm{PA}$ is one aspect of the broader concept of patient-centered care, which requires that clinicians focus on and attend to the needs, concerns, beliefs, values, goals and preferences of the patient $[10,11,14,15]$. To successfully support self-management and effective lifestyle change, healthcare providers require favorable attitudes, beliefs and skills regarding PA. This includes the ability to conduct a personalized approach to assessment; empower patient choice and practice collaborative goal setting; enhance patient skills to conduct specific health behaviors and selfmonitor; encourage patients to enable resources that support their goals; and provide ongoing follow-up and support [16].

Hibbard et al. [1] developed and tested the patient Activation Measure (PAM), a 22-item instrument which assesses patient or consumer self-reported knowledge, skills and confidence for self-management of one's health or chronic condition. In 2005, a 13-item short form of the PAM was developed with the same psychometric properties as the longer version and found being reliable and valid too [17]. It was validated via Rasch psychometric methods, and a unidimensional probabilistic Guttman-like scale was constructed [18] with a demonstrated validity and reliability [1,19-21]. The PAM divides consumers and patients into one of four progressively higher activation levels, which are associated with specific self-care and other health related behaviors. Research has repeatedly shown that a higher score on the PAM is positively associated with various health keeping related behaviors, such as preventive care and lifestyle behaviors, information seeking and use of health information, health outcomes and healthcare use, monitoring and medication adherence, conduct in the patientprovider encounter and self-management [22,23].

\section{PAM and Medical Conditions}

\section{PAM and Self-referral to inpatient treatment (SRIT)}

People with severe mental disorders occasionally need treatment from inpatient services in phases with increased symptoms and crises. A flexible, safe and predictable support from the services will facilitate the patients' coping in those phases [24]. Self-referral to inpatient treatment (SRIT) might be one way to obtain that [25]. SRIT has recently been implemented in several Community Mental health Centers (CMHC) in Norway [26-31]. This intervention is based on legislation regarding patients' rights [32], personalized care planning [33] and shared decision making [34]. SRIT seems already to be a flexible model adapted to patients' needs [30]. A recent study by Moljord et al. [28] in Norway, employed PAM13 in a total of 290 adult out-patients waiting for treatment in community mental health centers (CMHC) and found it useful for assessing patient knowledge, skills and confidence in management of chronic conditions, such as mental health. Their conclusion was that PAM had appropriate and acceptable psychometric properties in mental health settings. They also reported that assessing activation before treatment might be useful for scheduling the delivery of mental health services as well as evaluating educational interventions aimed at improving patient engagement in mental health. On the other hand, the same researchers, Moljord et al. [35] reported on a randomized controlled trial with 53 adult patients. From those participants, 26 persons received a SRIT contract, which they could use to refer themselves into a Community Mental Health Centre up to five days for each referral without contacting a doctor in advance. After 12 months with PAM13, there were no group differences, but both groups maintained their baseline levels.

\section{PAM and Chronic Pain}

Chronic pain is usually referred to as persistent pain lasting for three months or more with a majority of individuals reporting symptoms beyond one year [36]. Chronic pain is characterized by extensive and fluctuating symptoms $[36,37]$ with a broad impact on quality of life, and thus it requires a range of strategies for self-management [38]. Nost et al. [39] investigated the effects after twelve months related to patient activation and a range of secondary outcomes on persons with chronic pain of a chronic pain self-management course compared to a low-impact outdoor physical activity, delivered in an easily accessible healthcare service in public primary care. The intervention group was offered a group-based chronic pain self-management course with 2.5-h weekly sessions for a period of six weeks, comprising education that included cognitive and behavioral strategies for pain management, movement exercises, group discussions and sharing of experiences among participants. The control group was offered a drop-in, low-impact, outdoor physical activity in groups in one-hour weekly sessions that included walking and simple strength exercises for a period of six weeks. The primary outcome was PA assessed using the PAM13. Secondary outcomes included 
assessments of pain, anxiety and depression, pain self-efficacy, sense of coherence, health-related quality of life, well-being and the 30-s Chair to Stand Test. After twelve months, there were no statistically significant differences between the intervention and the control group for the primary or the secondary outcomes. Within both of the groups, there were statistically significant improvements in pain experienced during the previous week, the global self-rated health measure and the 30-s Chair to Stand Test. No long-term effect of the chronic pain self-management course was found in comparison with a low-impact physical activity intervention for the primary outcome patient activation or for any secondary outcome.

\section{Weight management intervention (WMI), cardiac rehabilitation (CR) and PAM}

Barnason etal. [40] determined whether a weight management intervention (WMI) plus cardiac rehabilitation (CR) compared to CR alone, improves outcomes for overweight and obese cardiac revascularization patients. Despite participating in cardiac rehabilitation (CR), few cardiac patients lose enough weight to achieve clinically significant cardiovascular disease risk reduction. This was a randomized controlled design with measurements at baseline, 4 and 6 months. Adults who had undergone either coronary artery bypass surgery (CABS) or percutaneous coronary intervention (PCI) and participated in a rural CR programs were recruited. Subjects were randomized to a 12-week telehealth WMI or control group. The primary outcome was weight loss. Secondary outcomes included physical activity, patient activation, perceived self-efficacy and use of weight management behaviors. A total of 43 subjects participated. The WMI group had significantly more weight loss averaged across the 4 and 6 months of $13.8( \pm 2.8)$ pounds compared to the control group [mean $=7.8( \pm 2.2)$ pounds]. There were no significant differences in physical activity (activity counts or daily minutes in moderate or more intense activity). The WMI group had significantly higher levels of patient activation. They also had significantly higher total scores on the Diet and Exercise Self-Management survey, and subscales that included self-efficacy for specific eating habits and managing diet behavior.

\section{Chronic Obstructive Pulmonary Disease (COPD) patients and PAM}

The treatment and management of chronic health conditions such as COPD is the most significant challenge for health systems around the globe. There is a wealth of evidence suggesting that self-management interventions improve patient outcomes [41]. Self-management behaviors refer to the practices of activities that individuals initiate and perform on their own behalf in the interest of maintaining and continuing health and well-being [42]. Yadav et al. [43] reported that COPD is associated with multiple health problems including physical and psychological impairment as well as socioeconomic deprivation. COPD can be managed if selfmanagement efficiency and disease management knowledge of patients is improved. Lewis et al. [44] evaluated whether a 4-week education and exercise programme offered to COPD patients with Medical Research Council (MRC) dyspnea 1-2, improves disease self-management. Patients were recruited by their GP to attend four weekly 2-h sessions provided by a multidisciplinary team. Patients completed outcome measures before and after the program. Forty-two patients entered the programme and 26 out of 42 (61.9\%) completed all sessions. The Bristol COPD Knowledge Questionnaire and PAM improved (both $\mathrm{p} \leq 0.001$ ). Disease burden was not reduced according to the COPD assessment test. All patients accepted a referral for ongoing exercise. Fourteen current smokers (81.3\%) accepted a referral for smoking cessation, three patients with anxiety or depression (37.5\%) accepted a psychological therapies referral. The programme improved COPD disease knowledge, patient activation and stimulated referrals to further services supporting disease management. Randomized controlled trials are warranted for similar interventions for COPD patients with early stage disease.

\section{Inflammatory bowel disease and PAM}

Lima et al. [45] intended to measure the scores of psychemotional constructs and self-management in patients with inflammatory bowel diseases (IBD), compare those scores according to the type of IBD, and verify the influence of these measures on self-management in health. This was a crosssectional study performed at the outpatient clinic of a public hospital. The patients were adults and diagnosed with IBD; they answered instruments of measure of self-esteem, anxiety and depression, health status and of activation. They evaluated 65 patients and they found high score of activation (average $=57.5$; $\mathrm{SD}=13.38$ ) and high score of self-esteem (average $=31.58 ; \mathrm{SD}=$ 4.98 ), moderate score of anxiety (average $=8.24 ; \mathrm{SD}=4.38$ ) and low score of depression (average $=5.47 ; \mathrm{SD}=3.53$ ). Significant correlations were observed, from low to moderate magnitude, between the other measures and activation $(p<0.05)$. There were weak correlations between activation and time since diagnosis; anxiety and number of comorbidities $(p<0.05)$. They have concluded that patients with IBD presented high self-esteem, moderate levels of anxiety, low levels of depression and a high level of activation. Longer time since diagnosis was related with better self-management in health.

\section{Parkinson's disease and PAM}

Parkinson's disease (PD) is a progressive neurological illness that impacts various aspects of life. Integration of medical and self-management in a collaborative approach to care is needed to enhance functioning and the quality of life of PD patients. In developing an integrated care program at a tertiary PD clinic, Kessler et al. [46] used a co-design process to gather stakeholder input. This was a cross-sectional mixed methods study using surveys and interviews. Patient and caregiver participants from the clinic completed two questionnaires to evaluate perceived receipt of self-management support (Patient Assessment of Care for Chronic Conditions) and activation for managing their 
health condition (Patient or Caregiver Activation Measure). A subset of these participants and healthcare providers took part in semi-structured interviews. Fifty-seven PD patients and thirty caregivers completed the questionnaires. Thirteen patients, six caregivers, and six healthcare providers were interviewed. 58\% of participants were moderately to highly activated to manage their lives with PD. Participants' perceptions of self-management support varied but was lacking in dimensions of goal setting and follow-up support/coordination. Qualitative analysis revealed four overarching themes related to experiences of managing PD: activation, self-management support, coordinated care, and access to services. This first study to explore patient activation in PD found high levels of activation but moderate to low levels of self-management support. The co-design process highlighted important aspects of a more collaborative approach to care.

\section{LDL reduction and PAM}

Atherosclerotic cardiovascular disease (ASCVD) remains the leading cause of mortality among US adults [47]. Liu et al. [48] analyzed survey data collected as part of a randomized clinical trial conducted from 2011 to 2014 of four financial incentive interventions to reduce low density lipoprotein cholesterol (LDL-C) among patients at risk for atherosclerotic cardiovascular disease. The main trial included 1503 patients aged 18-80 and recruited from primary care practices affiliated with three health systems. Participants were randomized into four groups: patient financial incentives, primary care physicians (PCPs) incentives, patients and PCPs shared incentives, or no incentives for LDL-C control. Patient Activation Measure (PAM) and Treatment SelfRegulation Questionnaire (TSRQ) surveys were administered at baseline and 12 months. Clinical outcomes were change in LDL-C at 12 and 15 months and average medication adherence as measured by electronic pill bottle opening. Mean changes in PAM and TSRQ scores were compared between patients eligible and not eligible for incentives. Clinical outcomes were tested against baseline and change in psychosocial measures using bivariate and multivariate regression. Change in PAM score and TSRQ autonomous sub score did not differ significantly between patients eligible and not eligible for incentives. Lower baseline and greater increase in TSRQ autonomous sub score were predictive of greater 15-month decrease in LDL-C. A financial incentive intervention to improve LDL-C control was not associated with changes in patients' activation or autonomous motivation. Increases in patient autonomous motivation are predictive of long-term LDL-C control.

\section{Dysglycaemia and PAM}

Terkildsen-Maindal et al. [49] validated the Danish translation of the PAM13 in a Danish population with dysglycaemia. 358 people with screen-detected dysglycaemia participated responded to PAM13. The Danish version of PAM13 formed a unidimensional, probabilistic Guttman-like scale explaining $43.2 \%$ of the variance. They did, however, find a different item sequence compared to the original scale. They reported that further development should focus on single items, response categories in relation to ceiling effects and further validation of reproducibility and responsiveness.

\section{Arthritis, rheumatoid arthritis and PAM}

McBain et al. [50] aimed to establish receipt and provision of self-management support for patients with inflammatory arthritis in the UK, and to establish whether receipt of self-management support is associated with patient's knowledge, skills, and confidence to self-manage. Questionnaires for patients and health care professionals were sent to members and associates of the National Rheumatoid Arthritis Society. Patients completed the PAM and questions about receipt of self-management support. Health care professionals completed the Clinician Support PAM and questions about provision of self-management support. A total of 886 patients and 117 health care professionals completed the survey. Only $15 \%$ of patients had attended a structured selfmanagement program. More than half of the patients reported having the skills, confidence, and knowledge to self-manage, and this skill set was associated with receipt of self-management support that was embedded in routine care. All health care professionals felt that patients should be actively involved in their own care, but $60 \%$ were unable to offer structured selfmanagement support. Health care professionals reported engaging in more embedded self-management support than patients reported receiving in routine care.

Moreover, web-based self-management enhancing programs have the potential to support patients with rheumatoid arthritis (RA) in their self-management; for example, improve their health status by increasing their self-efficacy or taking their prescribed medication. Zuidema et al. [51] developed a Web-based selfmanagement enhancing program in collaboration with RA patients and professionals as co-designers on the basis of the intervention mapping framework. This study aimed to evaluate the efficacy of a Web-based self-management enhancing program for patients with RA and identify outcome measures most likely to capture potential benefits. A multicenter exploratory RCT was performed with an intervention group and a control group. Both groups received care as usual. In addition, the intervention group received 12 months of access to a Web-based self-management program. Assessment occurred at baseline, 6 months, and 12 months. Outcome measures included self-management behavior (Patient Activation Measurement, Self-Management Ability Scale), self-efficacy (Rheumatoid Arthritis task-specific Self-Efficacy, Perceived Efficacy in Patient-Physician Interaction), general health status (RAND-36), focus on fatigue (Modified Pain Coping Inventory for Fatigue), and perceived pain and fatigue (Numeric Rating Scales). No positive effects were found regarding the outcome measurements. Effect sizes were low. Based on these results, it is not possible to conclude on the positive effects of the intervention or to select outcome measures to be regarded as the primary/main or secondary outcomes for a future trial. 


\section{PAM and heart failure}

Heart failure (HF) is a chronic, progressive condition, affecting individuals' and families' quality of life and increasing health care utilization and expenditures. An estimated 6.5 million Americans 20 years of age or older have HF, with prevalence projected to increase 46 percent by 2030 . In ambulatory patients with $\mathrm{HF}$, health literacy, HF knowledge and patient activation may be important characteristics that promote self-management. In one report, health literacy was associated with HF self-care scores [52]; however, in multiple reports, health literacy was associated with knowledge, [53-56] but not with self-care. In 2 reports, patient's HF self-care confidence was a mediator between health literacy and self-care $[52,55]$. Jacobson et al. [56] reported that more evidence is needed about factors that influence self-management behaviors in persons with heart failure. They tested a correlational mediation model of the independent variables of health literacy, patient activation, and heart failure knowledge with heart failure self-management behaviors. Heart failure self-management behaviors of 151 participants were positively correlated with PA level, but not with health literacy or heart failure knowledge. They concluded that persons with heart failure may better manage their condition if sufficiently activated, regardless of their level of health literacy or knowledge of heart failure disease and management processes.

\section{PAM and type II Diabetes Mellitus}

Van Vugt et al. [57] explored the relationship between insulin use and patient activation (a person's internal readiness and capabilities to undertake health-promoting actions) in individuals with type 2 diabetes mellitus and aimed to identify demographic, clinical and psychosocial factors involved in patient activation. In this cross-sectional study, baseline data from a Dutch nationwide study were analyzed. Patient activation was assessed with the PAM13. In total, 1,189 persons were included (310 of whom were on insulin), enrolled via 47 general practices and six hospitals. Their mean PAM13 score was $59 \pm 12$. They found no association between insulin therapy and patient activation. In the multivariable analysis, individuals with a better health status, very good or very poor social support (vs good social support), individuals who felt they had greater control over their illness and those with a better subjective understanding of their illness showed higher PA. Individuals with a lower educational level and those who expected their illness to continue showed a lower PA level. PA does not differ between individuals with type 2 diabetes mellitus on insulin therapy and those on other therapies.

Kosar \& Besen [58] used the PAM into a Turkish setting. Research sample consisted of 130 patients who had diabetes, hypertension or rheumatoid arthritis. They concluded that PAM has enough validity and reliability for use in determining activation scores and level of the patients in Turkey. It could be used in planning appropriate interventions for the activation level and help to improve self-management. Laranjo et al. [59] also performed PAM in Portuguese people with type 2 diabetes mellitus. There were 193 respondents with a response rate for the final questionnaire at $76 \%$. The sample was low to moderate in terms of activation: $40.4 \%$ were low in activation (levels 1 and 2), $49.7 \%$ were in level 3 , and $9.8 \%$ were in level 4 , the highest level of activation. They concluded that PAM13 was translated and culturally adapted to European Portuguese and validated in people with diabetes, showing good psychometric properties.

\section{PAM and healthcare utilization system}

PAM piloted for the first time in the NHS between 2014 and 2016 by five commissioners and the renal registry in England. Previous research has shown that more activated patients have lower healthcare costs [22] and better health outcomes than other patients. No studies have considered healthcare systems that are free at the point of use, such as the NHS in the UK, which also has a prominent role for primary care as a gatekeeper to secondary and specialized care. Most studies have focused on the link between the PAM and emergency and inpatient utilization of secondary care [60]. Furthermore, no studies have explicitly considered how mental health, physical health, multimorbidity or socioeconomic deprivation (which in England is measured at the area of patient's residence level using the Index of Multiple Deprivation 2010 (IMD) [61] influences the relationship between activation and utilization.

Barker et al. [62] aimed to quantify the association between patient self-management capability measured using the PAM and healthcare utilization across a whole health economy. 12.270 PAM questionnaires were returned from 9348 patients. In the adjusted analyses, compared with the least activated group, highly activated patients (level 4) had the lowest rate of contact with a general practitioner, emergency department attendances, emergency hospital admissions and outpatient attendances. These patients also had the lowest relative rate (compared with the least activated) of 'did not attends' at the general practitioner, 'did not attends' at hospital outpatient appointments and selfreferred attendance at emergency departments for conditions classified as minor severity, significantly shorter average length of stay for overnight elective admissions, and a lower likelihood of 30- day emergency readmission, though this did not reach significance. They concluded that self-management capability is associated with lower healthcare utilization and less wasteful use across primary and secondary care. Also, Rademakers et al. [63] translated PAM into a Dutch version. Psychometric properties of the Dutch version were established, and the PAM 13 was validated in a panel of chronically ill patients. It was sent to 4178 members of the Dutch National Panel of people with chronic illness or disability. Dutch results were compared to Danish and American data. The level of internal consistency was good and item-rest correlations were moderate to strong. The Dutch mean PAM score 
(61.3) was comparable to the American (61.9) and lower than the Danish (64.2) (Table 1). The association with health literacy was weak to moderate. They reported that the PAM13 Dutch was a reliable instrument to measure patient activation.

Table 1: Comparison of the Dutch PAM13 to the Danish, US, Norway, Canada, Turkish and Portuguese version.

\begin{tabular}{|c|c|c|c|c|c|c|c|}
\hline & $\begin{array}{c}\text { PAM13 Dutch } \\
\text { [63] }\end{array}$ & $\begin{array}{c}\text { PAM13 } \\
\text { Danish } \\
{[\mathbf{2 0}]}\end{array}$ & $\begin{array}{c}\text { PAM13 } \\
\text { USA } \\
{[\mathbf{2 2}]}\end{array}$ & $\begin{array}{c}\text { PAM13 Nor- } \\
\text { way } \\
{[\mathbf{2 8}]}\end{array}$ & $\begin{array}{c}\text { PAM13 Can- } \\
\text { ada } \\
\text { [64] }\end{array}$ & $\begin{array}{c}\text { PAM13 } \\
\text { Turkish } \\
\text { [58] }\end{array}$ & $\begin{array}{c}\text { PAM13 Portu- } \\
\text { guese } \\
\text { [59] }\end{array}$ \\
\hline Sample (N) & 1837 & 344 & 454 & 273 & 120 & 130 & 193 \\
\hline Mean Activation Score & 61.3 & 64.2 & 61.9 & 51.93 & 59.4 & $-58,5$ \\
\hline $\begin{array}{c}\text { Self-reported health (excel- } \\
\text { lent) }\end{array}$ & 74.2 & 76.3 & 68.7 & - & - & - \\
\hline $\begin{array}{c}\text { Internal consistency (Cron- } \\
\text { bach } \alpha \text { ) }\end{array}$ & 0.88 & 0.89 & 0,91 & 0.86 & 0.76 & 0.83 & - \\
\hline $\begin{array}{c}\text { Test-retest reliability (ICC) or } \\
\text { inter-item correlation }\end{array}$ & 0.47 & 0.38 & - & 0.76 & - & - & - \\
\hline
\end{tabular}

Self-reported health is the most distinguishing variable with respect to the patient activation scores, both in the Netherlands as in Denmark and the United States.

Internal consistency was measured as the Cronbach's $\alpha$ and inter-item correlations. Cronbach's $\alpha$ for the sum scale was 0.88 , which is similar to the Danish version (0.89) and is considered as a good level of internal consistency.

Test-retest reliability $(n=60)$ was calculated via the intraclass correlation coefficient $(I C C)$. Test-retest reliability was moderate in the Dutch study compared to Norway.

\section{PAM and Primary care}

Primary care providers (PCPs) can support self-management by providing information and encouragement on health behaviors and skills, and by encouraging the collaborative development of care plans that take into account patients' priorities and preferences. However, it is uncertain how frequently self-management support is provided, or how effective it is in increasing PA. McCusker et al. [64] aimed to examine: 1) whether patient characteristics predict perceived self-management support (usefulness of information and collaborative care planning) by primary care providers after six months, and 2) the association between perceived selfmanagement support and patient activation at 6 months They conducted a secondary analysis among 120 primary care patients aged 40 and over with a chronic physical condition and comorbid depressive symptoms who participated in a randomized controlled trial of a coaching intervention for depression self-management. Activation was measured at baseline (T0) and 6 months (T1). Self-management support was captured at T1 for physical and mood problems. The sample of analysis was 120 patients who completed all relevant measures. At T1, the perceived usefulness of information for mood self-management was independently associated with activation. More severe depressive symptoms at T0 predicted lower perceived usefulness of chronic condition selfmanagement information at T1. Lower T0 mental health-related quality of life predicted lower perceived usefulness of mood selfmanagement information at T1. It was concluded that perceived informational support for mood self-management may contribute to increased activation. Patients with more severe mental health symptoms or impairment perceive that they receive less useful self-management information from their care team.

\section{The role of PAM instrument in patient coaching}

As mentioned above, researchers were testing the PAM in countries such as the Netherlands, Norway, Denmark, Turkey, Portugal, UK and USA. They examined PA among adults with chronic conditions and in primary care settings [19-21,63,6569]. The validation of PAM 13 has been examined across adults with chronic conditions $[19,63,65]$, among multimorbid older adults [67], in a surgery setting ([66], in neurological populations $[21,70]$, among a diabetes population $[20,59]$, on patients with osteoarthritis [69], in a primary care setting [71] and for chronic disease in rural settings [72]. It seems that PA instruments, like PAM, are the current trend in personal patient health coaching. Of course, there are most often communication barriers in the interaction between patient and medical specialist thus leaving professionals only with the practical therapeutic plan, not having time and expertise to support ethically the patient most of the times.

It should be kept in mind that the interaction between patientdoctor is reported to relate to the patient's communication state after diagnosis. After diagnosis, patients ideally move through three consecutive communication states: 1) overwhelmed, passive; 2) pro-active, self-motivated; and 3) proficient, empowered. In the empowered state, patients have learned what questions they 
want to ask and how to ask those [71]. This fact could be utilized in order for patients to submit the PAM in this last stage so as to diminish bias from this kind of researches. However, since not all patients reach the third state; this evolution depends on various factors, like personal attributes and previous experiences and most relevant researchers have not yet taken full account of this fact. Furthermore, it was stated recently that patient health coaching is supposed to have a positive effect on patient-medical specialist communication [72]. It also seems that older patients, interested in a coach, are significantly older, have lower health literacy skills and less self-efficacy and, overall, experience more communication barriers, than patients without such interest [72].

Additionally, it should be noted that there is a novel and promising approach to patient coaching by performing a peercoaching model, in which patients with chronic pain, who are successfully managing their pain offer information, support, and advice to other patients, with the goal of helping them more effectively manage their pain. Three attributes are believed to define peer interventions: provision of: 1) emotional (caring, encouragement), 2) informational (advice, problem-solving), and 3) appraisal support (motivation to "keep going") [73]. Peer support models are effective in the management of a variety of chronic conditions, including diabetes, mental health and chronic pain [74-80], but are not yet tested for oral and maxillofacial diseases. In the field of coaching a lot of instruments are applied in order to enliven the accountability issue of the coachee (here the patient) so as to lead him to a healthier life and diet model. From the previous review process, it was revealed that an instrument such as PAM13 in patient coaching has been proven to bring behavioral alterations to the patients facing almost every major chronic disease. Thus, it should be an interesting point of research to apply the instrument in the field of dentistry, since no relevant data can be found accordingly.

\section{Prospects of PAM13 in the dental field}

In the dental field the two major chronic diseases are caries and periodontitis leading to pain, discomfort and finally tooth loss. It is reported that a person may experience five stages of grief when losing his teeth partially or completely. The first stage of loss is denial which is closely followed by anger. The third stage of bereavement is bargaining. This is followed by depression which is the most difficult stage to overcome and the final stage is acceptance where a person accepts the situation [81]. Davis et al. [82] concluded that many people have difficulty in terms of tooth loss and often feel less confident, restrict their social activities, and avoid forming close personal relationships. Studies done on completely and partially edentulous subjects have shown that teeth loss does not have a marked emotional effect but affected their daily social activities $[83,84]$. Loss of natural teeth not only influences oral function but also influences the social life and social activities, leading to a decline in psychological wellbeing [85]. Tooth loss is very traumatic and upsetting and is regarded as a serious life event that requires significant social and psychological readjustment [86]. Teeth have a symbolic significance, and loss of teeth may reflect impending loss of facial attractiveness and body degeneration [87]. Frustration sets in when a person starts to experience the difficulties that come with losing teeth, and only then, they truly realize the value of what was lost. Also, other entities, like temporomandibular joint dysfunctions, causing severe pain sometimes as well as other autoimmune diseases and vitamin deficiencies with oral symptoms can be checked for PA with the PAM instrument. This is expecting to help patients benefit through changes in the diet and lifestyles and helping them to keep healthy dental and oral tissues up to the third age period of their lives. More research then is required for the adaptation and validation of the PAM13 in dentistry, especially with respect to a more comprehensive measure of health literacy as reported by other researchers in the medical field [88-91].

The adapted Dental PAM (D-PAM) instrument should: a) Assess the patient's clinical and psychosocial risk for current and future oral disease; b) Explore and confirm specific patient behaviors (and the knowledge, beliefs, and attitudes associated with specific behaviors that contribute risk for disease progression); c) Rank these specific behaviors in terms of their contribution to poor oral health outcomes; d) Assess a person's motivation to alter their behavior; e) Effectively communicate physical oral disease findings and explain to patients how altering specific concrete behaviors could result in better oral health (and possibly systemic health); and f) Coach the patient in such a way that they are motivated, actively involved, and working collaboratively with their provider (over time) to act on plans to initiate and maintain behaviors that promote optimal oral health [91]. It should be noted finally, that in dental/oral health coaching, patients are the experts and they should be responsible of personal strategies relevant to their oral health. This differs substantially from the traditional oral/general health education whereby the dentist/physician is the expert who usually provides standardized information for all patients. The coach always makes a request before offering advice/ information, reflecting and empowering the idea that the patient is in control and also facilitating the patient's resourcefulness to make decisions and to learn. Moreover, the transfer of knowledge is designed specifically for the patient's goals; these must be in accordance with the patient's needs, expectations and daily life. It may be summarized that HC is a personalized, future oriented, self-exploring journey in which the patient is guided and motivated by the coach while sterile health education is usually about giving standardized health advice based on external motivation with the patient passively participating [92]. All this could explain how health coaching can be more effective than health education and why should future dental professionals learn through integrated lessons in their educational programs, the basic rules of coaching. By using dental/oral health coaching, people will achieve positive outcomes at earlier stages of the oral diseases, before costly expenses arise. This will be a benefit for both the health-care 
systems and patients while the latest will enjoy nice smiles and functional ability throughout their life span.

\section{Conclusion}

PAM13 succeeds in improving the general health of patients with chronic diseases. Patients can benefit from coaching through its use. It seems that people with mental, heart or chronic pain problems may require more support for self-management from their care teams. Improved access for national primary care systems' doctors to self-management tools can facilitate skillsdevelopment of the patient. Importantly, oral health application of PAM13 should be checked as a future research tool for controlling oral health diseases that contribute to loss of teeth, like caries, periodontitis and peri-implantitis.

\section{References}

1. Hibbard JH, Stockard J, Mahoney ER, Tusler M (2004) Development of the Patient Activation Measure (PAM): conceptualizing and measuring activation in patients and consumers. Heal Serv Res 39(4): 1005-1026.

2. Cinar AB, Freeman R, Schou L (2018) A new complementary approach for oral health and diabetes management: health coaching. Int Dent J 68(1): 54-64.

3. WHO (2018)?

4. Wagner EH (1998) What will it take to improve care for chronic illness? Eff Clin Pract 1(1): 2-4.

5. Wagner EH (2000) The role of patient care teams in chronic disease management, Br Med J 320: 569.

6. Wagner EH, Austin BT, Davis CR, Hindmarsh M, Schaefer J, et al. (2001) Improving chronic illness care: translating evidence into action, Health Aff 20(6): 64-78.

7. Holman H, Lorig K (2000) Patients as partners in managing chronic disease. Br Med J 320(7234): 526-527.

8. Higgins R, Murphy BM, Worcester MU, Daffey A, (2012) Supporting chronic disease self-management: translating policies and principles into clinical practice. Aust J Prim Health 18(1): 80-87.

9. Battersby M, Ask A, Reece MM, Markwick MJ, Collins JP, et al. (2003) The Partners in Health scale: the development and psychometric properties of a generic assessment scale for chronic condition selfmanagement. Aust J Prim Health 9: 41-52.

10. Michie, Miles SJ, Weinman J (2003) Patient-centeredness in chronic illness: what is it and does it matter? Patient Educ Counsel 51(3): 197206.

11. Pelzang R, (2010) Time to learn: understanding patient-centered care. Br J Nurs 19(14): 912-917.

12. Kitson A, Marshall A, Bassett K, Zeitz K (2013) What are the core elements of patient-centered care? A narrative review and synthesis of the literature from health policy, medicine and nursing. J Adv Nurs 69(1): 4-15.

13. Richards T, Couter A, Wicks P (2015) Time to deliver patient centered care. Br Med J pp. 350.

14. Entwistle VA, Cribb A, Watt IS, Skea ZC, Owens J, Morgan HM, et al. (2018) The more you know, the more you realise it is really challenging to: Tensions and uncertainties in person-centered support for people with long-term conditions. Patient Educ Counsel 101: 1460-1467.
15. Hibbard JH, Collins PA, Mahoney E, Baker LH (2010) The development and testing of a measure assessing clinician beliefs about patient selfmanagement. Health Expect 13(1): 65-72.

16. Fisher EB, Brownson CA, O’Toole ML, Shetty G, Anwuri VV, Glasgow RE, et al. (2005) Ecological approaches to self-management: the case of diabetes. Am J Public Health 95(9): 1523-1535.

17. Hibbard JH, Mahoney ER (2010) Toward a theory of patient and consumer activation. Patient Education and Counseling 78(3): 377381.

18. Andrich D (2005) Rasch Models for Ordered Response Categories. Wiley Online Library.

19. Zill JM (2013) Psychometric evaluation of the German version of the patient activation measure (PAM13). BMC Public Health 13 -1027.

20. Maindal HT, Sokolowski I, Vedsted P (2009) Translation, adaptation and validation of the American short form Patient Activation Measure (PAM 13) in a Danish version. BMC Public Health 9: 209.

21. Stepleman L (2010) Validation of the patient activation measure in a multiple sclerosis clinic sample and implications for care.Disabil Rehabil 32(19): 1558-1567.

22. Hibbard JH, Mahoney ER, Stockard J, Tusler M (2005) Development and testing of a Short Form of the Patient Activation Measure. Heal Serv Res 40(6 Pt 1): 1918.

23. Rask KJ, Ziemer DC, Kohler SA, Hawley JN, Arinde FJ, Barnes C, et al. (2009) Patient activation is associated with healthy behaviours and ease in managing diabetes in an indigenous population. The Diabetes Educator 35(4)-622.

24. Rise MB, Westerlund H, Bjorgen D, Steinsbekk A (2014) Safely cared for or empowered in mental health care. Yes, please, Int J Soc Psychiatry 60(2): 134-138.

25. Strand M, von Hausswolff-Juhlin Y (2015) Patient-controlled hospital admission in psychiatry: a systematic review. Nord J Psychiatry 69(8): 574-586.

26. Heskestad S, Tytlandsvik M (2008) Patient-guided crisis admissions for severe psychotic conditions. Tidsskr Nor Laegeforen 128(1): 32-35.

27. Rise MB, Evensen GH, Moljord IE, Ro M, Bjorgen D, Eriksen L, et al. (2014) How do patients with severe mental diagnosis cope in everyday life - a qualitative study comparing patients' experiences of selfreferral inpatient treatment with treatment as usual. BMC Health Serv Res 14: 347 .

28. Moljord IE, Helland-Hansen KA, Salvesen O, Olso TM, Gudde CM, Rise MB, et al. (2016) Short time effect of a self-referral to inpatient treatment for patients with severe mental disorders: A randomized controlled trial. BMC Health Serv Res 16-513.

29. Sigrunarson V, Moljord IE, Steinsbekk A, Eriksen L, Morken G, et al. (2016) A randomized controlled trial comparing self-referral to inpatient treatment and treatment as usual in patients with severe mental disorders. Nord J Psychiatry 1-6.

30. Olso TM, Gudde CB, Moljord IE, Evensen GH, Antonsen DO, Eriksen L, et al. (2016) More than just a bed: mental health service users' experiences of self-referral admission. Int J Ment Health Syst 10-11.

31. Støvind H, Hanneborg EM, Ruud T (2012) Bedre tid med brukerstyrte innleggelser? ('Better time with user-controlled admissions'), Sykepleien 100: 62-64.

32. Health, Care Department, Lov Om Pasient- Og Brukerrettigheter, Health and Care Department, Oslo, 1999 (Law in patient- and user rights) 07-02-63. 


\section{Advances in Dentistry \& Oral Health}

33. Coulter A, Entwistle VA, Eccles A, Ryan S, Shepperd S, Perera R et al. (2015) Personalised care planning for adults with chronic or long-term health conditions. Cochrane Database Syst Rev Cd010523.

34. Duncan E, Best C, Hagen S (2010) Shared decision-making interventions for people with mental health conditions. Cochrane Database Syst Rev (Online) 3: Cd007297.

35. Moljord IEO, Lara-Cabrera ML, Salvesen O, Rise MB Bjørgen D, Antonsen DO et al. (2017) Twelve months effect of self-referral to inpatient treatment on patient activation, recovery, symptoms and functioning: A randomized controlled study. Patient Education and Counseling 100(6): 1144-1152.

36. Brien TO, Breivik H (2012) The impact of chronic pain-European patients' perspective over 12 months. Scand J Pain 3(1): 23-29.

37. Breivik H, Eisenberg E, Brien TO (2013) The individual and societal burden of chronic pain in Europe: the case for strategic prioritisation and action to improve knowledge and availability of appropriate care. BMC Public Health 13-1229.

38. Newman S, Steed L, Mulligan K (2004) Self-management interventions for chronic illness. Lancet 364:1523-37.

39. Nøst TN, Steinsbekk A, Bratås 0, Grønning K (2018) Twelve-month effect of chronic pain self-management intervention delivered in an easily accessible primary healthcare service- a randomised controlled trial. BMC Health Services Research 18(1): 1012.

40. Barnason S, Zimmerman L, Schulz P, Pullen C, Schuelke S, et al. (2019) Weight management telehealth intervention for overweight and obese rural cardiac rehabilitation participants: A randomised trial. J Clin Nurs 28(9-10): 1808-1818.

41. Vestbo J, Hurd SS, Agustí AG, Cones PW, Vogelmeier C, et al. (2013) Global strategy for the diagnosis, management, and prevention of chronic obstructive pulmonary disease: GOLD executive summary. Am J Respir Crit Care Med 187(4): 347-365.

42. Orem DE, Taylor SG, Renpenning KM (2001) Nursing Concep Prac. $6^{\text {th }}$ edn St. Louis: Mosby pp. 402.

43. Yadav U, Hosseinzadeh NH, Baral KP (2018) Self-management and patient activation in COPD patients: An evidence summary of randomized controlled trials. Clinical Epidemiology and Global Health 6(3): 148-154.

44. Lewis A, Dullaghan D, Townes H, Green A, Potts P, et al. (2019) An observational cohort study of exercise and education for people with chronic obstructive pulmonary disease not meeting criteria for formal pulmonary rehabilitation programmers. Chronic Respiratory Disease 16: 1479973119838283

45. Lima ADS, De Almeida-Neto OP, Cunha CM (2018) Measurement of psycho-emotional constructs and self-management in health of patients with inflammatory Bowel diseases. Biosci. J., Uberlândia 34: $1775-1785$.

46. Kessler D, Hauteclocque J, Grimes D, Mestre T, Coted D, et al. (2019) Development of the Integrated Parkinson's Care Network (IPCN): using co-design to plan collaborative care for people with Parkinson's disease. Quality of Life Research 28(5): 1355-1364.

47. (2016) National Center for Health Statistics. Health, United States, With Chartbook on Long-Term Trends in Health. MD, Hyattsville, 2017.

48. Liu T, Volpp KG, Asch DA, Zhu J, Wang W, et al, (2019) The association of financial incentives for low density lipoprotein cholesterol reduction with patient activation and motivation. Preventive Medicine Reports 14: 100841 .

49. Terkildsen Maindal H, Sokolowski I, Versted P, (2009) Translation, adaptation and validation of the American short form Patient Activation
Measure (PAM 13) in a Danish version. BMC Publ Health 9: 209.

50. McBain H, Shipley M, Newman S (2018) Clinician and Patient Views about Self-Management Support in Arthritis: A Cross-Sectional UK Survey. Arthritis Care \& Research 70(11): 1607-1613.

51. Zuidema R, Van Dulmen S, Van der, Sanden MN, Meek I, et al. (2019) Efficacy of a Web-Based Self-Management Enhancing Program for Patients with Rheumatoid Arthritis: Explorative Randomized Controlled Trial. J Med Internet Res 21(4): 1-16.

52. Zou H, Chen Y, Fang W, Zhang Y, Fan X (2017) Identification of factors associated with self-care behaviors using the COM-B model in patients with chronic heart failure. Eur J Cardiovasc Nurs 16(6): 530-538.

53. Dennison CR, McEntee ML, Samuel L (2011) Adequate health literacy is associated with higher heart failure knowledge and self-care confidence in hospitalized patients. J Cardiovasc Nurs 26: 359-367.

54. Chen AM, Yehle KS, Albert NM, Ferraro KF, Mason HL (2013) Health literacy influences heart failure knowledge attainment but not selfefficacy for self-care or adherence to self-care over time. Nurs Res Pract 2013: 353290 .

55. Chen AM, Yehle KS, Albert NM, Ferraro KF, Mason HL, et al. (2014) Relationships between health literacy and heart failure knowledge, self-efficacy, and self-care adherence. Res Soc Adm Pharm 10(2): 378386.

56. Jacobson AF, Sumodi V, Albert NM, Butler RS, DeJohn L, et al. (2018) Patient activation, knowledge, and health literacy association with selfmanagement behaviors in persons with heart failure. Heart \& Lung 47(5): 447-451.

57. Van Vugt HA, Boels AM, De Weerdt I, JP de Koning E, EHM Rutten (2019) Patient activation in individuals with type 2 diabetes mellitus: associated factors and the role of insulin. Patient Preference and Adherence 13: 73-81.

58. Kosar C, Besen BP (2019) Adaptation of a patient activation measure (PAM) into Turkish: reliability and validity test. African Health Sciences 19(1): 1811-1820.

59. Laranjo L, Dias V, Nunes C, Paiva D, Mahoney B (2018) Translation and Validation of the Patient Activation Measure in Portuguese People with Type 2 Diabetes Mellitus. Acta Med Port 31(7-8): 382-390.

60. Shively MJ, Gardetto NJ, Kodiath MF, Kelly A, Smith TL et al. (2013) Effect of patient activation on self-management in patients with heart failure. J Cardiovasc Nurs 28(1): 20-34.

61. (2011) Department for Communities and Local Government. English indices of deprivation 2010.

62. Barker I, Steventon A, Williamson R, Deeny SR (2018) Self-management capability in patients with long-term conditions is associated with reduced healthcare utilisation across a whole health economy: crosssectional analysis of electronic health records. BMJ Qual Saf 27(12): 989-999.

63. Jany Rademakers, Jessica Nijman, Lucas van der Hoek, Monique Heijmans, Mieke Rijken (2012) Measuring patient activation in the Netherlands: translation and validation of the American short form Patient Activation Measure (PAM13). BMC Public Health 12: 577.

64. McCusker J, Lambert SD, Haggerty J, Yaffe MJ, Belzile E, et al. (2019) Selfmanagement support in primary care is associated with improvement in patient activation. Patient Education and Counseling 102(3): 571577.

65. Mosen DM (2007) Is patient activation associated with outcomes of care for adults with chronic conditions? J Ambul Care Manag 30(1): 21-29. 


\section{Advances in Dentistry \& Oral Health}

66. Skolasky RL (2009) Psychometric properties of the Patient Activation Measure among individuals presenting for elective lumbar spine surgery, Qual Life Res 18(10): 1357-1366.

67. Skolasky RL (2011) Psychometric properties of the patient activation measure among multimorbid older adults, Health Serv Res 46(2): 457478.

68. Brenk Franz K (2013) Validation of the German version of the patient activation measure 13 (PAM13-D) in an international multicentre study of primary care patients, PLoS ONE 8: e74786.

69. Ahn YH (2014) Psychometric properties of the Korean version of the Patient Activation Measure 13 (PAM13-K) in patients with osteoarthritis, Eval Health Prof 38(2): 255-264.

70. Packer TL (2015) The Patient Activation Measure: a validation study in a neurological population, Qual Life Res 24(7): 1587-1596.

71. Van Bruinessen IR, Van Weel-Baumgarten EM, Gouw H, Zijlstra JM, Albada A, et al. (2013) Barriers and facilitators to effective communication experienced by patients with malignant lymphoma at all stages after diagnosis. Psychooncology 22(12): 2807-2814.

72. Alders I, Smits C, Brand P, Van Dulmen S (2017) Does patient coaching make a difference in patient-physician communication during specialist consultations? A systematic review. Patient Educ Couns 100(5): 882-896.

73. Dennis CL (2003) Peer support within a health care context: a concept analysis. Int J Nurs Stud 40: 321-332.

74. Heisler M, Piette JD (2005) I help you, and you help me: facilitated telephone peer support among patients with diabetes. Diabetes Educ 31(6): 869-879.

75. Heisler M, Vijan S, Makki F, Piette JD (2010) Diabetes control with reciprocal peer support versus nurse care management: a randomized trial. Ann Intern Med 153(8): 507-516.

76. Piette J, Resnicow K, Choi H, Heisler M (2013) A diabetes peer support intervention that improved glycemic control: mediators and moderators of intervention effectiveness. Chron Illn 9(4): 258-267.

77. Chinman M, Oberman RS, Hanusa BH, Cohen AN, Salyers MP, et al. (2013) A cluster randomized trial of adding peer specialists to intensive case management teams in the veteranshealth administration. J Behav Health Serv Res 42: 109-121.

78. Foster G, Taylor SJC, Eldridge S, Ramsay J, Griffiths CJ, et al. (2007) Selfmanagement education programmes by lay leaders for people with chronic conditions. Cochrane Database Syst Rev 4: CD005108.

79. Lorig KR, Laurent DD, Deyo RA, Marnell ME, Minor MA, et al. (2002) Can a backpain e-mail discussion group improve health status and lower health care costs? a randomized study. Arch Intern Med 162(7) 792-796.
80. Lorig KR, Ritter PL, Laurent DD, Plant K (2008) The internet-based arthritis self-management program: a one-year randomized trial for patients with arthritis or fibromyalgia. Arthritis Care Res 59(7): 10091017

81. Goodman S, Got Teeth? A Survivor Guide. How to Keep your Teeth or Live Without Them. Dog Ear Publishing, USA.

82. Davis DM, Fiske J, Scott B, Radford RD (2000) The emotional effects of tooth loss: A preliminary quantitative study. Br Dent J 188: 503-6.

83. Shah RJ, Diwan FJ, Diwan MJ, Chauhan VJ, Agrawal HS, et al. (2015) A study of the emotional effects of tooth loss in an edentulous Gujarati population and its association with depression. J Indian Prosthodont Soc 15(3): 237-43.

84. Naik AV, Pai RC (2011) Study of emotional effects of tooth loss in an aging north Indian community. ISRN Dent 2011: 395498.

85. Emami E, De Souza RF, Kabawat M, Feine JS (2013) The impact of edentulism on oral and general health. Int J Dent 2013: 498305.

86. Omar R, Tashkandi E, Abduljabbar T, Abdullah MA, Akeel RF, et al (2003) Sentiments expressed in relation to tooth loss: A qualitative study among edentulous Saudis. Int J Prosthodont 16: 515-20.

87. Allen PF, McMillan AS (2003) A review of the functional and psychosocial outcomes of edentulousness treated with complete replacement dentures. J Can Dent Assoc 69(10): 662.

88. Williams GC, Rodin GC, Ryan RM, Grolnick WS, Deci EL, et al. (1998) Autonomous regulation and long-term medication adherence in adult outpatients. Health Psychol 17(3): 269-276.

89. Williams GC, Patrick H, Niemiec CP (2009) Reducing the health risks of diabetes: how self-determination theory may help improve medication adherence and quality of life. Diabetes Educ 35(3): 484-492.

90. Parchman ML, Zeber JE, Palmer RF (2010) Participatory decision making, patient activation, medication adherence, and intermediate clinical outcomes in type 2 diabetes: A STAR Net study. Ann Fam Med 8: 410-417.

91. Umeukeje EM, Merighi JR, Browne T (2015) Self-motivation is associated with phosphorus control in end-stage renal disease J Ren Nutr 25(5): 433-439.

92. Vernon LT, Howard AR (2015) Advancing Health Promotion in Dentistry: Articulating an Integrative Approach to Coaching Oral Health Behavior Change in the Dental Setting. Curr Oral Health Rep 2: 111-122. 
This work is licensed under Creative Commons Attribution 4.0 License DOI: 10.19080/ADOH.2020.12.555833
Your next submission with Juniper Publishers will reach you the below assets

- Quality Editorial service

- Swift Peer Review

- Reprints availability

- E-prints Service

- Manuscript Podcast for convenient understanding

- Global attainment for your research

- Manuscript accessibility in different formats

( Pdf, E-pub, Full Text, Audio)

- Unceasing customer service

Track the below URL for one-step submission https://juniperpublishers.com/online-submission.php 